\title{
„BIERZESZ CZTERY LUB PIĘĆ NUT, JEDNĄ WYRZUCASZ, JEDNĄ PRZESUWASZ...", czyli temat główny z Gwiezdnych wojen i Marsz imperialny jako standardy muzyki filmowej oraz ich wpływ na kulturę popularną
}

Patryk SKORUPSKI Wydział Pedagogiczno-Artystyczny w Kaliszu, Uniwersytet im. Adama Mickiewicza w Poznaniu

\section{ABSTRACT}

YOU GET FOUR OR FIVE NOTES, YOU TAKE ONE NOTE OUT AND ONE MOVE AROUND...*, "STAR WARS MAIN THEME" AND "IMPERIAL MARCH" AS STANDARDS OF FILM MUSIC AND THEIR INFLUENCE ON POPULAR CULTURE

Everybody has his own smells, tastes, pictures which are associated to us with particular situations. It is the same with music and melodies. Most of us can hum "Ode to Joy", "Für Elise" or... "Imperial March" from Star Wars. What is the strongest quality of music from this saga? Dynamism? Simplicity? Or maybe tone of instruments? I will try to find reason.

\section{SŁOWA KLUCZOWE:}

Star Wars, music, soundtrack, popular culture, orchestra, movie, commercial

* The Best Film Composer Quotes [online], 16 marca 2015 [dostęp: 20 lutego 2017]. Dostępny w World Wide Web: http://www.classicfm.com. 
Gwiezdne Wojny łączą moje dwie pasje: film i muzykę, którą zajmuję się zawodowo. W niniejszym artykule postanowiłem połączyć te oba obszary. Kompozytor muzyki filmowej Ennio Morricone powiedział kiedyś: „Nikt, kto chce mówić o kinie, nie może ignorować muzyki filmowej - stanowi ona bowiem integralną część naszego życia, naszych czasów, współczesnej kultury”'. Wiele melodii z filmów weszło do kanonu muzyki popularnej, stało się ikonami, które każdy potrafi zanucić. Większość z nas zna motyw przewodni serii filmów o Jamesie Bondzie, temat towarzyszący przygodom Harry'ego Pottera czy... Marsz imperialny z Gwiezdnych wojen. Postaram się odnaleźć przyczynę fenomenu dwóch najsłynniejszych tematów galaktycznych.

Twórca Gwiezdnych Wojen, George Lucas, zyskał popularność w 1973 roku za sprawą młodzieżowego filmu Amerykańskie graffiti. Kolejne cztery lata poświęcił na pracę nad pierwszym filmem z serii Star Wars. Robocza ścieżka dźwiękowa zawierała wybrane przez Lucasa fragmenty muzyki angielskiego kompozytora Gustava Holsta, tworzącego na przełomie XIX i XX wieku. Ostatecznie reżyser zdecydował, że muzykę do filmu stworzy John Williams. Kompozytor zasłynął dwa lata wcześniej ścieżką dźwiękową do filmu Szczęki Stevena Spielberga. Lucas miał jedną wskazówkę dla Williamsa - pragnął, aby otwierająca całość kompozycja zawierała „bębny wojenne

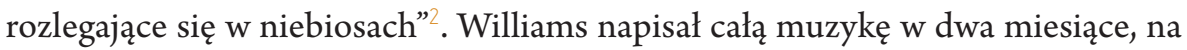
początku 1977 roku, dwa dni zaś trwało nagranie jej przez Londyńską Orkiestrę Symfoniczną ${ }^{3}$.

Otwierający temat był dziki i pompatyczny. Ciekawym posunięciem kompozytora była zmiana z budzącej grozę tonacji molowej Holsta na pełną radości i podniecenia tonację durową. Nadal słychać jednak w kompozycji Williamsa analogię do suity Holsta. Co stanowi o sile motywu przewodniego? Potężne fanfary orkiestry symfonicznej świetnie korespondują z wielkimi napisami przelatującymi w kosmosie. Ciekawostką jest, że Lucas myślał nawet o wykorzystaniu nowatorskiej w tamtym czasie muzyki heavymetalowej ${ }^{4}$.

Spróbujmy przeanalizować zapis nutowy tego tematu. Pierwsza część składa się z zaledwie pięciu dźwięków i nietrudnych interwałów (czyli skoków pomiędzy dźwiękami), przetworzonych w różnej kolejności. Ten czterotaktowy motyw jest zagrany dwa razy.

M. Brączyk, Kochanek X Muzy, „Tygodnik Przegląd” [online], 24 lipca 2005 [dostęp: 20 lutego 2017]. Dostępny w World Wide Web: https://www.tygodnikprzeglad.pl/kochanek-x-muzy/.

Ch. Taylor, Gwiezdne wojny - jak podbity wszechświat?, Znak Horyzont, Kraków 2015, s. 210.

Tamże.

Ł. Trykowski, Muzyka z Trylogii [online], 5 marca 2004 [dostęp: 20 lutego 2017]. Dostępny w World Wide Web: http://star-wars.pl/Tekst/524. 

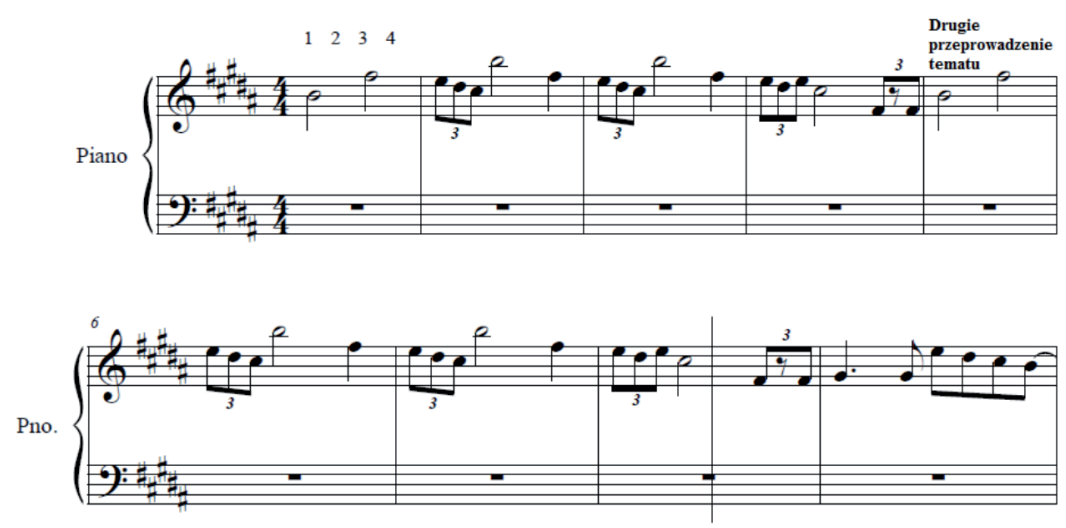

Następnie rozpoczyna się kolejny temat, również powtórzony, po nim wracamy do pierwszego motywu.
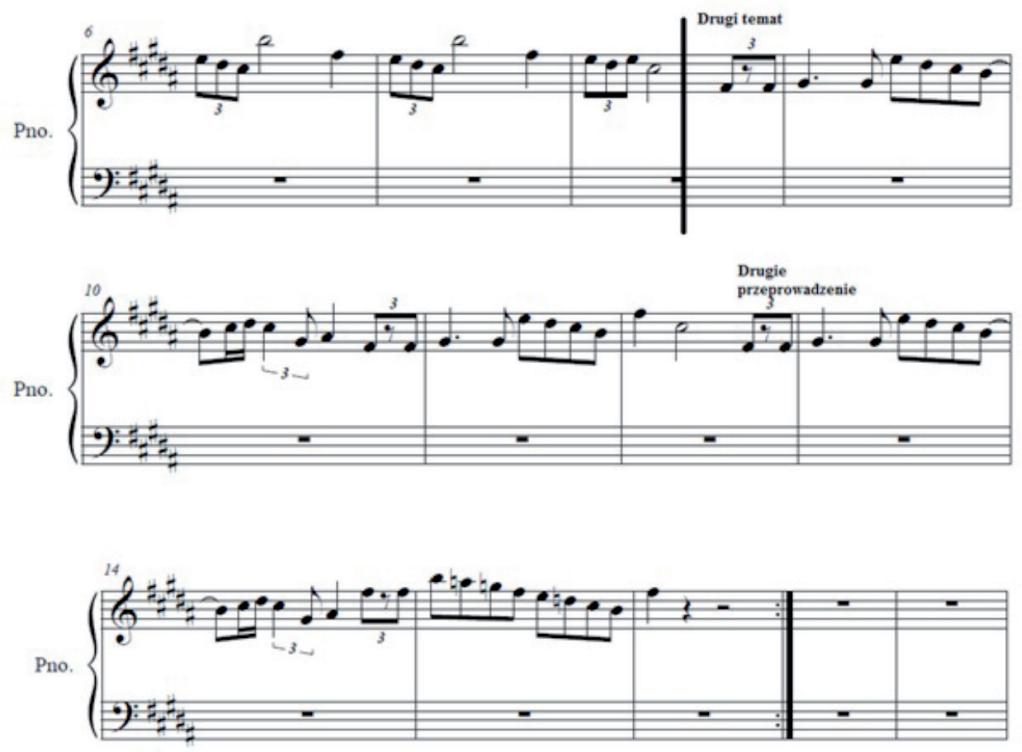

Całość utrzymana jest w tonacji B-dur oraz metrum 4/4, co oznacza, że każdy takt liczymy do czterech. 
Jak powiedział kiedyś zacytowany w tytule tego artykułu John Williams: „Bierzesz cztery lub pięć nut, jedną wyrzucasz, drugą przesuwasz, jeszcze inną dodajesz”. Kompozytor nie silił się na wyszukane melodie, z prostych rzeczy tworząc chwytliwe tematy. Dzięki temu dotarł do tak ogromnej rzeszy słuchaczy. Ruch melodii był prosty, każdy mógł go zrozumieć. Ubierając ścieżkę dźwiękową w dostojne brzmienia instrumentów orkiestry symfonicznej, uczynił ją niebanalną.

Co ciekawe, każdy z ośmiu (jak na razie) epizodów Star Wars zawiera inne wykonanie motywu przewodniego. Williams do każdej części nagrywał całą muzykę, nawet jeśli niektóre tematy pojawiły się już w poprzednich obrazach.

Za sukcesem pierwszego filmu przyszedł sukces ścieżki dźwiękowej. Williams otrzymał Nagrodę Brytyjskiej Akademii Filmowej, Oscara, Złoty Glob, Saturna, Nagrodę Stowarzyszenia Krytyków Filmowych z Los Angeles oraz trzy statuetki Grammy ${ }^{5}$.Jesienią 1977 roku, przez prawie dwa tygodnie, soundtrack byl przebojem numer $1 \mathrm{w}$ kilku amerykańskich rozgłośniach radiowych. Triumfy święciło również Star Wars Theme w wersji disco zespołu Meco ${ }^{6}$.

Siedemnastego maja 1980 roku na ekrany kin weszła kolejna część przygód Luke’a Skywalkera, księżniczki Lei i Hana Solo - Imperium kontratakuje. Film dojrzalszy, mroczniejszy, pełen efektów specjalnych i doskonałych ujęć. W początkach filmu po raz pierwszy na ekranie pojawia się Executor - osobisty Okręt Lorda Vadera. Widzimy też samego Vadera na pokładzie statku. Tej scenie towarzyszy słynny Imperial March, nazywany inaczej Darth Vader's Theme'.

Temat złowrogiego Imperium jest również zbudowany $\mathrm{w}$ bardzo prosty sposób. Początek motywu składa się tylko z trzech dźwięków, melodia prowadzona jest w kierunku wznoszącym oraz opadającym i stworzona na zasadzie zawołania i odpowiedzi.

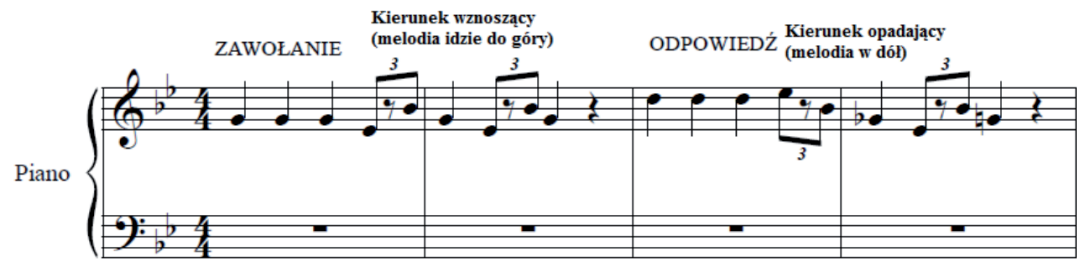

John Williams Awards [online], [dostęp: 20 lutego 2017]. Dostępny w World Wide Web: http://www. imdb.com/name/nm0002354/awards.

Ch. Taylor, dz. cyt., s. 258.

I. Kershner (reż.), Gwiezdne wojny: Imperium kontratakuje (Star Wars: Empire Strikes Back), USA 1980. 
Po czterotaktowym motywie pojawia się kolejny, który jest wariacją na temat pierwszego i zostaje powtórzony.
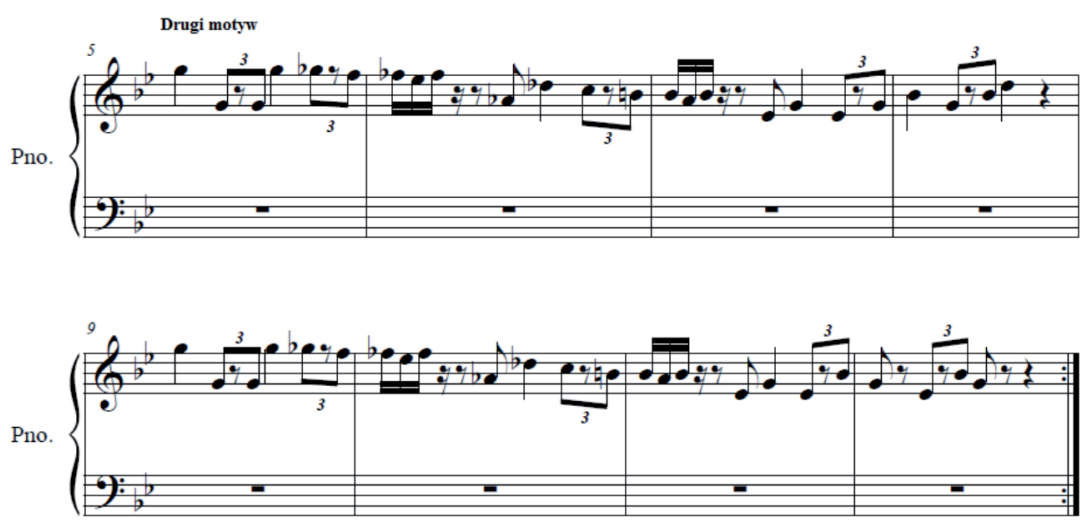

Mroczny klimat wywołuje smutna tonacja g-moll. W motywie przeważa prostota i oszczędność dźwięków, które przez stałe powtarzanie wprowadzają słuchacza w ponurą mantrę. Ponownie mamy metrum 4/4. Marsz imperialny możemy usłyszeć we wszystkich częściach Gwiezdnych wojen, łącznie z spin-offem sagi-Rogue One z 2016 roku. Występuje on jako wariacja lub przetworzenie oryginalnego tematu. Pojawia się też w kilku odcinkach seriali Wojny klonów i Rebelianci, reżysera Dave’a Filoniego. Brzmi, kiedy na ekranie pojawia się Vader lub ktoś go wspomina. W Epizodach I-III motyw ujawnia się, kiedy omawiana jest przyszłość Anakina Skywalkera, lub towarzyszy wydarzeniom, które zwiastują nadejście Imperium.

Williams nagrał muzykę do filmu w dziewięć dni podczas trzydniowej sesji w grudniu 1979 roku oraz przez sześć dni w styczniu roku 1980. Ponownie towarzyszyła mu Londyńska Orkiestra Symfoniczna. Ścieżka dźwiękowa nie zdobyła tylu nagród co poprzedniczka, jednak jej twórcom udało się otrzymać Nagrodę Brytyjskiej Akademii Filmowej za najlepszą muzykę filmową oraz Grammy w kategorii Najlepszy album z oryginalną ścieżką dźwiękową napisaną dla filmu kinowego lub na potrzeby specjalnego programu telewizyjnego ${ }^{8}$. 
Zarówno Main Theme, jak i Imperial March doczekały się całego mnóstwa interpretacji muzycznych. Co więcej, liczba filmów, seriali, skeczy czy reklam, w których fragmenty obu kompozycji były wykorzystane, jest niezliczona. Przytaczam kilka z nich:

- metalowy cover zespołu Galactic Empire', w którym na gitarze prowadzącej gra Darth Vader, czy wspólne wykonanie melodii sagi przez aktorów Epizodu VII, Jimmy'ego Fallona i zespół The Roots ${ }^{10}$;

- własna wersja Marszu imperialnego grana przez zespół No Doubt na koncertach $^{11}$;

- motyw przewodni ze słynnymi napisami otwiera jeden z odcinków serialu Teoria wielkiego podrywu, w którym czterej nerdzi, wielcy fani Gwiezdnych wojen, próbują zdobyć bilet na przedpremierę Przebudzenia Mocy. Jest to jedno z wielu nawiązań do sagi w sitcomie ${ }^{12}$;

- temat Lorda Vadera towarzyszy jednemu z orzeszków M\&M’s, kiedy odmawia on przejścia na ciemną stronę w reklamie z 2005 roku $^{13}$;

- w reklamie baterii Duracell dwoje rodzeństwa walczy przeciw całemu Imperium na podwórku swojego domu przy wsparciu mieczy zasilanych reklamowanym produktem i przy słynnych fanfarach ${ }^{14}$.

Po 40 latach od premiery pierwszego filmu z serii Star Wars muzyka z sagi, tak jak wiele innych elementów, nie trąci myszką. Wciąż zaskakuje, inspiruje i porywa nowe pokolenia fanów. Sam George Lucas powiedział kiedyś, że muzyka jest jedyną częścią filmu, która przekroczyła jego oczekiwania. Jeden z grafików pracujących przy filmach Star Wars, Paul Bateman, określił dzieło Williamsa jako tlen Gwiezdnych wojen $^{15}$. Zgadzam się z nim w stu procentach.

9 Rise Records, Galactic Empire - Star Wars - The Imperial March [online], 4 maja 2016 [dostęp: 20 lutego 2017]. Dostępny w World Wide Web: https://www.youtube.com/results?search_query=star+wars+music.

10 The Tonight Show Starring Jimmy Fallon, Jimmy Fallon, The Roots \& "Star Wars: The Force Awakens” Cast Sing „Star Wars” Medley (A Cappella) [online], 15 grudnia 2015 [dostęp: 20 lutego 2017]. Dostępny w World Wide Web: https://www.youtube.com/watch?v=ZTLAx3VDX7g.

No Doubt, The Imperial March, Live in the Tragic Kingdom, Interscope Records, 1997.

Ch. Lorre, B. Prady (reż.), Big Bang Theory: The Opening Night Excitation, USA 2015.

M\&M’s Commercials: Mł'M's - Red's Decision, USA 2005 [online], [dostęp: 20 lutego 2017]. Dostępny w World Wide Web: https://www.youtube.com/watch?v=rfG3bcQZjSA.

14 Duracell Star Wars Commercial, USA 2015 [online], [dostęp: 20 lutego 2017]. Dostępny w World Wide Web: https://www.youtube.com/watch?v=C5W1_9i7YI8.

15 Ch. Taylor, dz. cyt., s. 211. 


\section{BIBLIOGRAFIA}

Kershner I. (reż.), Gwiezdne wojny: Imperium kontratakuje (Star Wars: Empire Strikes Back), USA 1980. Dostępny jako dodatek do „Gazety Wyborczej”, Warszawa 2015.

Taylor Ch., Gwiezdne wojny - jak podbity wszechświat?, Kraków 2015.

\section{PUBLIKACJE DOSTĘPNE W INTERNECIE}

Brączyk M., Kochanek X Muzy, „Tygodnik Przegląd” [online], 24 lipca 2005 [dostęp: 20 lutego 2017]. Dostępny w World Wide Web: https://www.tygodnikprzeglad.pl/kochanek-x-muzy/.

Duracell Star Wars Commercial, USA 2015 [online], [dostęp: 20 lutego 2017]. Dostępny w World Wide Web: https://www.youtube.com/watch?v=C5Wl_9i7YI8.

John Williams Awards [online], [dostęp: 20 lutego 2017]. Dostępny w World Wide Web: http://www.imdb.com/name/nm0002354/awards.

Lorre Ch., Prady B. (reż.), Big Bang Theory: The Opening Night Excitation, USA 2015. Dostępny w World Wide Web: https://www.youtube.com/watch?v=QeSpBNNLdw.

M\&M's Commercials: M\&'M's - Red's Decision, USA 2005 [online], [dostęp: 20 lutego 2017]. Dostępny w World Wide Web: https://www.youtube.com/ watch?v=rfG3bcQZjSA.

Rise Records, Galactic Empire - Star Wars - The Imperial March [online], 4 maja 2016 [dostęp: 20 lutego 2017]. Dostępny w World Wide Web: https://www.youtube. $\mathrm{com} /$ watch?v=nohQReM7BpI.

The Best Film Composer Quotes [online], 16 marca 2015 [dostęp: 20 lutego 2017]. Dostępny w World Wide Web: http://www.classicfm.com.

The Tonight Show Starring Jimmy Fallon, Jimmy Fallon, The Roots \& „Star Wars: The Force Awakens” Cast Sing „Star Wars” Medley (A Cappella) [online], 15 grudnia 2015 [dostęp: 20 lutego 2017]. Dostępny w World Wide Web: https://www.youtube. com/watch?v=ZTLAx3VDX7g.

Trykowski Ł., Muzyka z Trylogii, 5 marca 2004 [dostęp: 20 lutego 2017]. Dostępny w World Wide Web: http://star-wars.pl/Tekst/524. 